\title{
An Etymo-Cognitive Approach to Modern Greek Vocabulary Learning ${ }^{1}$
}

\author{
Alejandro García Aragón \\ University of Granada \\ aga@ugr.es
}

\begin{abstract}
Modern Greek textbooks generally introduce new vocabulary in very short contexts or long lists, and only sometimes do they provide the etymology of the vocabulary in order to give meaning to these 'empty' words. The etymo-cognitive approach aims to systematise and make explicit the semantic information that goes unnoticed in words sharing the same etymon. This is achieved using widely known words in the learner's mother tongue and by means of etymo-cognitive maps. These are graphical devices in which etymologically related words can be logically structured and grouped according to the activity, the course level, and the type of learners involved.
\end{abstract}

\section{Introduction}

The Structural Approach still predominates in standard textbooks addressed to Modern Greek (MG) learners. This approach was in fashion until the recent past: words and sentences were "presented and practised in a way which is intended best to help the learners to internalize them as forms containing meaning within themselves, as semantic capsules" (Widdowson 2002: 157). The assumption is that once learners have achieved this semantic knowledge through taught knowledge, they would be able to use it autonomously in communicative activities as in their mother tongue (L1).

It goes without saying that words or phrases are easier to remember in context rather than as independent items (Robinson 2003). In an attempt to contextualize

$\mathbf{1}$ This research has been carried out within the framework of the project RECORD: Representación del Conocimiento en Redes Dinámicas [Knowledge Representation in Dynamic Networks, FFI2011-22397], and supported by an FPU grant to the author (AP2009-4874), both funded by the Spanish Ministry for Science and Innovation.

\section{(cc) BY-NC-ND}


new lexical knowledge, MG vocabulary and its declensions, conjugations, and derivatives are generally learnt separately in very short contexts or simply out of context that students have to learn on their own account (cf. Ibáñez et al. 1997; Villar 1997).

Some MG textbooks include texts which may be preceded or followed by a list of 'unknown' or new vocabulary. However, if the textbook contains a great number of lists, or if their texts become increasingly longer, learners may encounter obvious recall or motivation problems. Besides, if the items on the lists are 'explained' by means of synonyms, whether in MG or other languages, there is the risk of including words that are more obscure than the word(s) they intend to explain. Not every synonym, if more than one is included, is adequate in any context or even in the text in which the 'explained' words are inserted. This may lead learners to believe that they are simpler or interchangeable synonyms or equivalences which are valid in any context (Hurtado 2007: 51).

Some textbooks provide complete linguistic information about each unknown word or idiom. However, this is not useful information for every student level, especially intermediate and advanced students who are supposed to have mastered the basic rules.

Other textbooks divide vocabulary into parts of speech. This may be helpful at first, but there are more efficient ways of organising it; for example, introducing new vocabulary by relating it to Ancient Greek roots in order to give meaning to these 'empty' words. However, this is done rather vaguely and never systematically.

\section{The Etymo-Cognitive Approach}

The etymo-cognitive approach (ECA) is the result of qualitative research aiming to make explicit a type of semantic information that goes unnoticed in the process of learning MG as a second language (L2), while improving traditional MG learning methods. This approach is based on both the internal and external structure of $M G$, i.e. roots or etymons ${ }^{2}$ and their word-forms or derivatives.

A large part of the Ancient Greek lexicon from around $800 \mathrm{BC}$ has survived in MG. It has undergone very few changes, especially from around $330 \mathrm{BC}$ on (from

2 By etymons and roots we mean complete words or isolated morphemes or letter strings which carry and transmit a basic or core concept(s) to other directly or indirectly related words, morphemes or letter strings, thus creating 'families' that can be normally identified by orthographical patterns. These core concepts are generally transmitted from etymon to etymon generally through metaphor, metonymy, derivation, analogy, and other cognitive and linguistic processes. 
Koine or 'Common' Greek), preserving and adapting its high morpheme-per-word ratio. The MG percentage of 'derivativeness' (or derivational synthesis) is thus higher than in other languages (cf. Rodríguez Adrados 1999; Polychrou 1997). As a consequence, the great number of derivatives is one of the most difficult obstacles a MG learner must overcome, as well as an ancient and apparently irrational orthography. However, this is only apparent because the greater the number of etymologically-related lexical units, the easier it is to group them.

Due to MG iotacism and other phonological phenomena, many words may sound similar, and similar-sounding words interfere with recall (Baddeley $\&$ Hitch 1974 apud Randall 2007: 17). For instance, the word/etymon hypothesis $=v \pi \delta ́ \theta \varepsilon \sigma \eta$ (from $v \pi \delta ́$ 'sub' $+\theta \dot{\varepsilon} \sigma \eta$ 'position'), is pronounced /ipó $\theta$ esi/. If the learner is to write down the word, there are several phonetically correct but orthographically incorrect ways to write it: $\imath \pi \delta ́ \theta \varepsilon \sigma l, \varepsilon \imath \pi \dot{\theta} \theta \varepsilon \sigma \eta, v \pi \dot{\theta} \theta \varepsilon \sigma l, v \pi \omega \dot{\varepsilon} \theta \alpha \iota \sigma l$, $\imath \pi \dot{\omega} \theta \varepsilon \sigma v, \eta \pi \dot{\theta} \theta \alpha \imath \sigma \varepsilon l, v \pi \dot{\theta} \theta \varepsilon \sigma \eta \ldots .$. However, only the last one is orthographically correct, and it is semantically motivated and relegates this word to a specific family. This identification is easier in some languages (e.g. English, French, German) than others (e.g. Spanish, Portuguese, Italian, Romanian) due to their orthographical systems. Even if users of the second group of languages knew the Greek origin of hypothesis, they would not know if the first $i$ corresponds to an upsilon $(v)$, if the $t$ corresponds to a theta $(\theta)$, and they may even wonder if the $z$ in Romanian or $s$ in Italian corresponds to a sigma $(\sigma)$ or a zeta ( $\zeta)$. Thus, knowledge of English and/or French is extremely useful when learning the orthography of a new MG word, since it would be easier for the learner to identify, retain, and thus transcribe and spell MG words/etymons. As a result, the learner's L1 lexicon coming from Greek etymons can be easily identified and thus exploited in order to improve mnemonics.

According to Goswami et al. (1997), the transparency of MG orthography may facilitate the recognition of smaller units within words. Our approach is based on the assumption that these smaller units frequently bear the same, or nearly the same, implicit semantic information. The shared semantic information between each etymon and its derivatives is made explicit through their orthography. For instance, 'lunch' ( $\mu \varepsilon \sigma \eta \mu \varepsilon \rho \imath \alpha v o ́)$ is pragmatically and etymologically related to

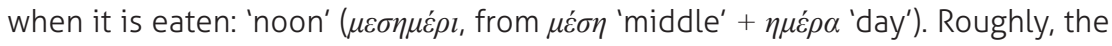
ancient word $\eta \mu \varepsilon \dot{\rho} \rho \alpha$ ('day') is found in many other MG words, such as $\eta \mu \varepsilon \rho \eta \dot{\sigma l o s, ~}$

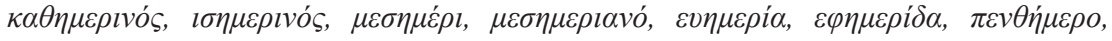
$\kappa \alpha \lambda \eta \mu \varepsilon \rho \alpha, \sigma \dot{\eta} \mu \varepsilon \rho \alpha, \varepsilon v \eta \mu \varepsilon \rho \omega ́ v \omega, \varepsilon \varphi \eta \dot{\mu \varepsilon \rho о \varsigma, ~ \eta \mu \varepsilon \rho о \mu \eta v i ́ \alpha, ~ \eta \mu \varepsilon \rho о \lambda o ́ \gamma l o, ~ e t c . ~ I n i t i a l l y, ~ t h e i r ~}$ corresponding meanings may not be interrelated in the learner's L1 vocabulary: daily, everyday, equator, noon, lunch, prosperity, newspaper, five-day, good morning, today, to update, ephemeral, date, calendar, etc. Nevertheless, there is a semantic relation to the concept DAY in these terms that is not evident in English. This phenomenon is more prominent in MG than in other languages, and we believe it should be structured and exploited for both natives and learners. 
Instead of taking MG etymology from a strict point of view, this approach takes advantage of widely known words in the learner's L1 whose etymons come from Ancient Greek roots (as with most European languages) and which are still used in MG. Thus, the learner's previous knowledge is transformed and re-directed in order to extract and underscore any shared meaning between the learner's L1 and MG.

In a nutshell, the ECA is based on both the internal (semantic) and external (orthographical) structure of MG, and more specifically on the following assumptions:

- MG has a higher percentage of 'derivativeness' (or derivational synthesis) in its lexical units than other languages;

- MG derivativeness implies having a greater number of etymologically related lexical units than in other languages;

- MG roots/etymons and their derivatives share at least a pattern-related orthography, and thus they can be grouped orthographically;

- MG derivatives frequently bear the same, or nearly the same, implicit semantic information through their etymons and their orthography, and thus can also be grouped semantically.

Graphical representations of mental models are based on categorization and are implemented in the etymo-linguistically motivated cognitive maps or etymo-cognitive maps (ECMs) proposed in section 4.

\section{Theoretical Underpinnings}

The ECA integrates part of the experientialist approach of Johnson (1987), Lakoff (1987) and Langacker (1987). Experientialism considers that language is based on the human experience of the real world, and thus language is seen as a tool of human cognition in order to convey meaning. Humans conventionalize and store cognitive categories in their brain, which constitutes the mental lexicon (Ungerer \& Schmid 1996: 38). Categorization is thus the basis for linguistic comprehension and production. Since categories are dynamic and are the basis for language, language itself is inherently symbolic and contextual. In turn, there is ambiguity between cognitive and linguistic categories because they are structured according to prototypical relations and family resemblances, consisting of more or less prototypical members of idealized cognitive models, i.e. schematic simplifications and understandings of the real world as perceived by humans (Lakoff 1982: 165).

It goes without saying that categorization and memory are highly interdependent facets of cognition (Heit 1997: 30). One important function of categorization is allowing inductive inferences or predictions about additional features (ibid.), and discovering hidden 'systematicity' in instances of apparent 
chaos or randomness (Lakoff 1987: 96). In this case, these ideas are applied to MG etymons/headwords of ECMs (central members of a map) and to prefixes, suffixes and other morphological changes or rules (which are the forms/shapes in which other family members are linked to the central members).

Multidimensionality or poly-dimensionality (cf. Bowker 1997; Kageura 1997. inter al.) then arises when there are various possibilities of classifying the same concept into the same conceptual system, which is the case for VEHICLE (Figure 1):

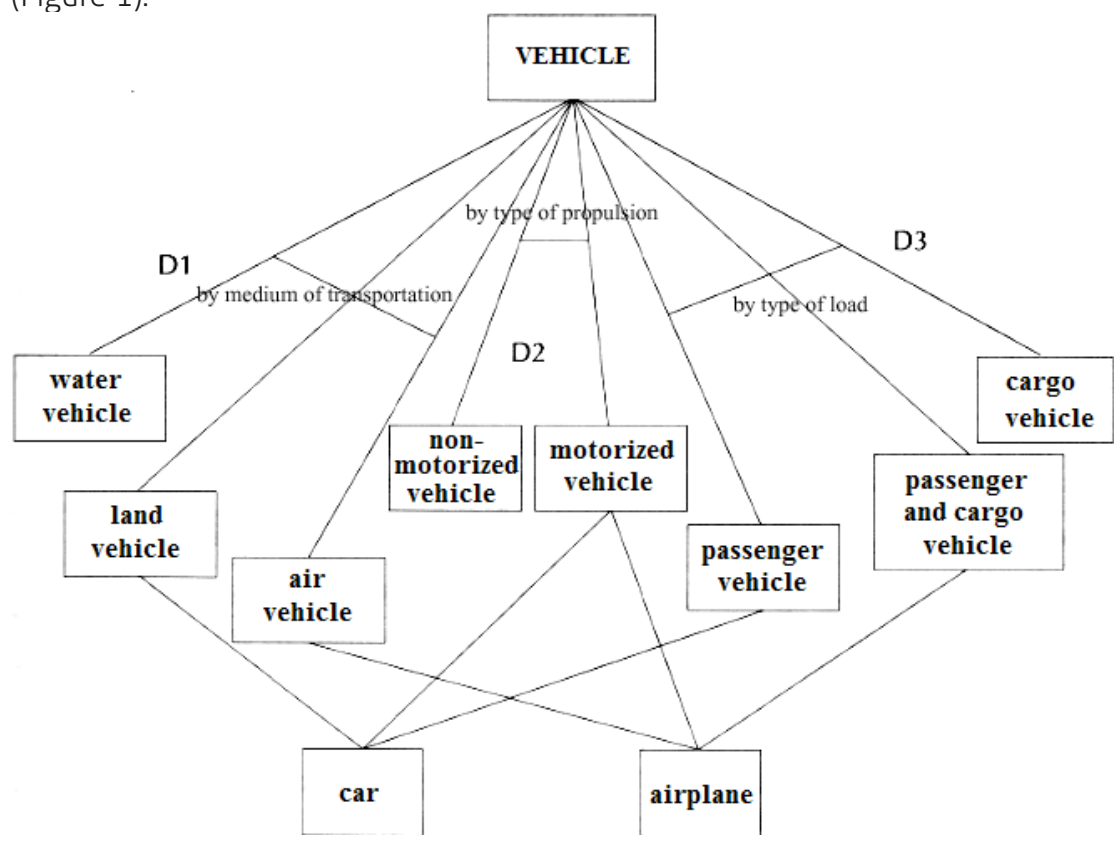

Figure 1. A multidimensional classification for vehicle

(adapted from Bowker 1997: 17; Faber \& Jiménez 2004: 71)

The concept CAR is thus represented from three points of view or dimensions. D1: medium of transportation, which categorizes CAR as a LAND VEHICLE; D2: type of propulsion, which categorizes CAR as a MOTORIZED VEHICLE; and D3: type of load, as a PASSENGER VEHICLE.

Our approach was heavily influenced by this notion, but also by the concept of graded structure (Barsalou 1987), which refers to a continuum of category representativeness, "beginning with the most typical members of a category and continuing through its atypical members to those nonmembers least similar to category members" (ibid.). Graded structure is central to predicting ease of category learning, with typical exemplars being easier to acquire than atypical exemplars (e.g. Rosch 1973, 1975, 1978; Mervis \& Pani 1980; Rosch, 
Simpson \& Miller 1976). In the following example, there is a graded structure of prototypicality of birds, from the most typical (robin, sparrow) to the most atypical exemplars (penguin, ostrich):

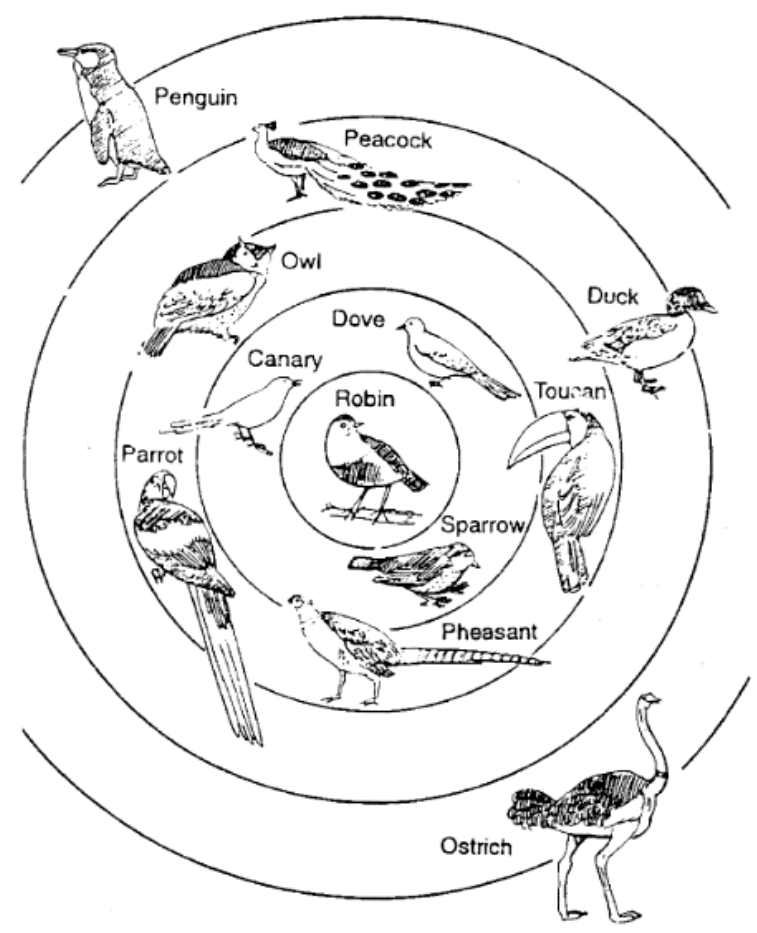

Figure 2. Prototype theory example: birdiness ranking

(Hatch \& Brown 1995: 58; Aitchison 2003: 54)

Graded structure goes hand in hand with conceptual salience and Relevance Theory (Sperber \& Wilson 1986), which argues that an assumption is irrelevant in a context to the extent that the effort required to process it in this context is large. Moreover, what you remember well depends heavily on the context in which you are exposed to it, how relevant it is to your life. This is why typical or almost universal Greek-rooted words in the learner's L1 should be included as the main infographical object of each etymo-cognitive map as symbolic units in a chain of family resemblance, multidimensionality, and prototypicality.

According to Nuopponen (apud Rogers 2004: 216), conceptual systems can be organized into three types: hierarchical, sequential and heterarchical. Rogers argues that the latter is a formal organisation of connected nodes (MG symbolic units), without any single permanent uppermost node (headwords in ECMs). This means that heterarchical systems are a type of interconnected and alternating 
instantaneous hierarchical conceptual systems, in the way that an ECM can behave. Our premise is that heterarchy depends on a situated-contextualized purpose-based conceptualization (Barsalou 2005). In this way, the permanence of a specific uppermost node or concept (etymon, headword of an ECM) depends on the situated knowledge purpose (task, exam, knowledge field, type of learner, etc.).

The interrelated cognitive abilities of category learning, inductive reasoning, and memory are significantly guided by people's background knowledge, including both specific knowledge and more general principles (Heit 1997: 33). With this in mind, representation and multidimensionality depend on who is classifying. Therefore, it is not surprising that different types of users may use different criteria to classify the same domain or knowledge node (Picht \& Draskau 1985: 48 apud Rogers 2004: 219).

According to Armstrong (2006: 31), learners have different intelligences or minds which can be developed and work jointly. This multiplicity of intelligences was explored as early as 1983 by Gardner, who initially established eight basic intelligences that everyone possesses in a unique way (Sygmund 2006: 35). Among these intelligences, or minds (Gardner 2008), the most important for our approach is the linguistic intelligence. This is vital in order to master MG vocabulary, declensions, orthography, and etymology, the most challenging parts for most learners. This kind of intelligence can benefit from ECMs as tools to organize and interrelate a substantial amount of linguistic information. In the process of structuring an ECM, the logical-mathematical type of learner can also benefit from considering etymons as meaningful symbols that can be logically structured. One of the most attractive features of ECMs is that they can integrate different colours, lines, shapes, space, and relations among them, and people with a prominent spatial intelligence have a special sensitivity to them. Besides, the emotional type of learner can benefit from choosing which kind of ECM suits best his personal interests or style (Gardner apud Armstrong 2006: 18-22; Robinson 2003; Sygmund 2006).

Moreover, the ECA is backed up by computational lexical access models. Following Forster's search model, each headword or head-concept of each ECM becomes a recognizable symbol that triggers at least three different codes, modules or access files to the master file, which is the mental lexicon. These access files (i.e. orthographic, phonological, syntactic-semantic files) are arranged in our mind in order of decreasing frequency and recent activation (cf. Forster's search model 1976, 1979, 1994 apud Randall 2007). The orthographic file is a crucial concept for our approach, since it is a starting point for the recognition of etymons, which are considered here as letter strings which bear a basic sense that relates every word that contains it.

These files or codes are linked and interact also in other word recognition theories, such as Seidenberg and McClelland's 1989 Triangle Model. According 
to these authors, there are three basic principles that need to be mastered by learners of English:

a) The alphabetic principle, which states that "there are systematic correspondences between the spoken and written forms of words" (Seidenberg \& McClelland 1989: 524). This principle can be fully applied to MG, since these correspondences are more systematic than in English.

b) The orthographic redundancy principle, which states that not all combinations of the letters of the alphabet are equally permissible. In MG, for

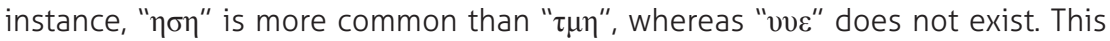
principle is very interesting for the ECA because it establishes whether a word belongs to the natural system of a language, and determines its frequency and recognisability of etymons.

c) The morphological redundancy principle, which states that not all combinations of the morphemes of a language are "equally permissible". This is also useful for our word recognition and the abundant derivative processes in MG. For example, the morpheme " $\omega \varsigma^{\prime}$ " may follow roots like "какós", and never the other way around.

Whereas single-route models like this assume that both regular and irregular morphology are processed by a single mechanism, dual-route models hold that morphologically regular words are processed by rules of inflectional concatenation, whereas irregular words are thought to be stored as wholes and can be accessed from lexical memory, such as Coltheart's et al. 2001 dual route model of "visual word recognition and reading aloud". Taft and Foster (1975 apud Randall 2007: 108) also argue that there is economy of storage involved in a morphological (root + affix) storage system. Regular derivatives are thus omitted in our approach, since they are stored as 'rules', not as 'lexicon'. On the contrary, irregular words or etymons are highlighted in order to help store them as 'wholes' and so that they may be accessed from lexical memory.

\section{Etymo-Cognitive Maps}

Etymo-cognitive maps (ECMs) are one of the most efficient implementations of the ECA. These are infographical maps in which the mentioned conceptterm relations can be logically structured in word clusters of etymologically related words. ECMs thus become representations of the individual's specific lexical structuring and understanding of a language, and are based on ad hoc categorizations and motivations. These maps are always heterarchical, and can be mono-, bi-, or multilingual depending on the learner's background and objectives, and the organization of ECMs is flexible and dynamic depending on the activity, the course level and the type of learner involved. 
ECMs cannot be domain-derived since they do not represent the relations shared by concepts in a specific (sub-)domain or event. Instead, ECMs represent a specific common meaning shared by the representation of different concepts. The main constraint is directionality, which must be from MG to the learner's L1. However, ECMs can be goal- and user-derived, as well as in continuous development.

We believe ECMs are a mnemonic improvement at various levels of knowledge-oriented and mental lexicon-inspired representations of the general lexicon of a language.

ECMs are useful in highlighting the abstract sense relations between lexical items, and thus can be used as frames of reference when comparing the learner's L1 and MG. Moreover, even though each infographical element or object seems to be isolated words or pairs of word-and-equivalent, this is far from being the whole story. Each object in each infographical node carries general intra- or interlinguistic relations (whose guiding thread are MG semes), thus helping learners establish subliminal 'equivalences' as well as 'differences' (because not every object must, or rather can, contain multilingual relations).

Semantic relations cannot be considered as a matter of objective truth, but instead as a matter of users' idiosyncratic mental representations of language, and processes involving them, and thus are not necessarily fixed in our minds but can be generated as needed (cf. Murphy 2003: 5, 42). In ECMs, the main semantic load is carried by and etymologically related to the head-concept/word. Then, this relation can be structured or grouped by any other relation(s), such as

part_of_speech: verb / adjective / noun, etc.

has_high / medium / low:frequency_in / relevance_for / number_of_derivatives, etc.

has_suffixes / prefixes / no_affixes

has_the_same_suffix / prefix_as

is_antonym / synonym_of

belongs_to > domain: GEOGRAPHY, MEDICINE, PHYSICS, etc.

belongs_to > (sub) language: dialect / jargon / Ancient Greek / region, etc.

These relations can be explicit or implicit in the maps.

We recommend each ECM be provided with an archi-lexeme or headword in MG that should comply with the basic cognitive level requirements (Kleiber 1990: 84-87). According to this author, the basic level words are rapidly identified because they are linked to a simple and global idea; these words are generally short, frequently used words, and thus they belong to neutral contexts, contain a great amount of information, and are easier to process. Moreover, prototypical categories can be fully developed from the basic level to the superordinate and 
subordinate levels (Ungerer \& Schmid 1996: 72). Therefore, each headword of an ECM should:

- be the nearest MG lexical unit to the general concept that the etymon evokes: e.g. preferably clinic to clinometer,

- have a typical equivalent/counterpart in the learner's L1, which is the case for clinic.

- be a complete MG lexical unit/etymon, not an isolated prefix or suffix (e.g.

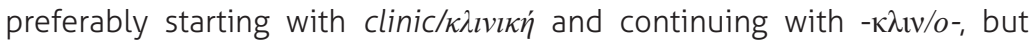
never starting with $\sigma v v-, \alpha \pi o-$ or $-\eta \sigma \eta$ ).

- be the shortest MG lexical unit with that etymon (e.g. preferably clinic to polyclinical). According to Baddeley and Hitch (1974 apud Randall 2007: 17), the word length effect shows that memory is better for short words than long words.

Accordingly, we also recommend that each etymologically related word:

- be less frequent than the headword;

- be preferably longer than the headword;

- have a higher degree of specificity than the headword, and thus less easily recognised by learners;

- be complete lexical units/etymons, not an isolated prefix or suffix.

\subsection{Creating an ECM}

When it comes to creating an ECM, e.g., for the etymon - $\kappa \lambda \imath v-$, we could start by taking the almost universally salient Greek-rooted word clinic ( $\kappa \lambda l v \imath \kappa \eta$ ) (Figure 7). This word is also shared by other languages such as English, Spanish, French, etc. In order not to miss all relevant words related to this specific etymon, a thorough analysis of a comprehensive mono- or bilingual dictionary of MG is extremely useful. A quick way of having a list of words containing that etymon is

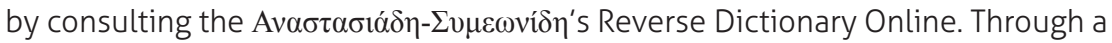

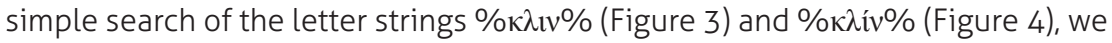
obtain an alphabetical word list.

These word lists are then analyzed in order to dismiss any word not including typical concepts evoked by $-\kappa \lambda \imath v$-: INCLINATION, DECLINATION, BED. Then, the resulting words can be individually checked against the web in order to see their frequency or relevance, in order to discard other words which are not found in current MG texts.

Dictionaries and the web can also be consulted in order to add definitions, alternative senses or frequent collocations. Monolingual dictionaries online,

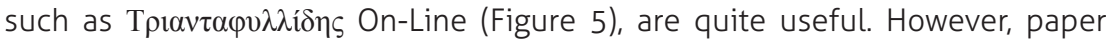
dictionaries are strongly recommended, such as M $\pi \alpha \mu \pi \imath \imath \omega \dot{\tau} \tau \varsigma$, in which a great amount of compounds and derivatives are provided (Figure 6). 


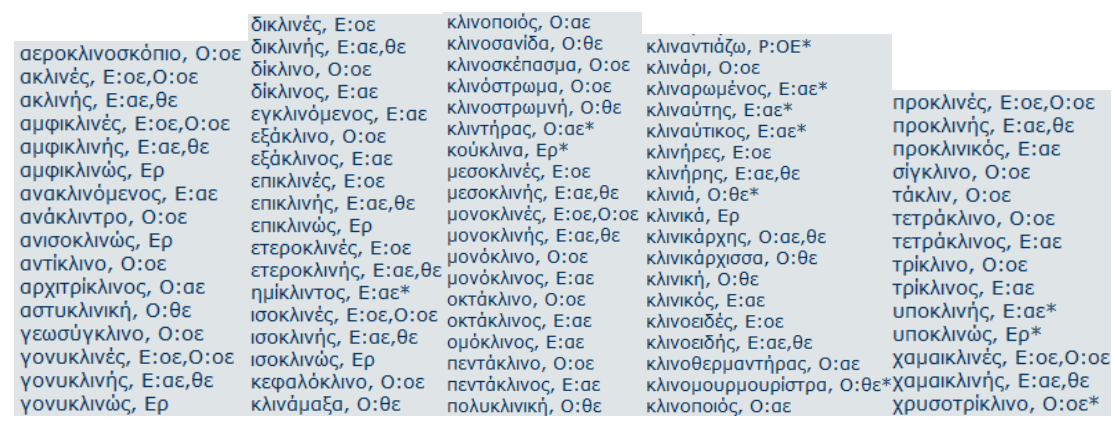

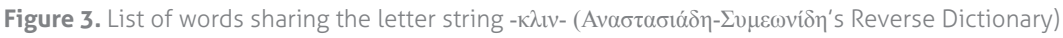

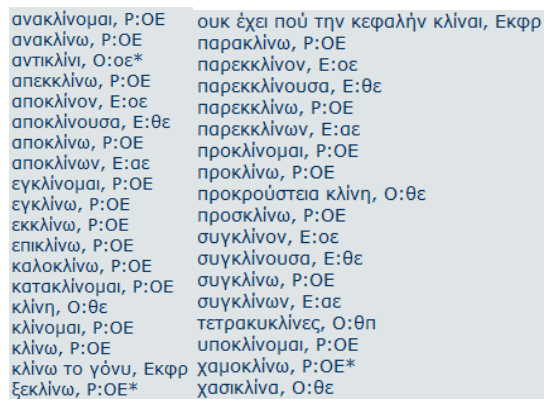

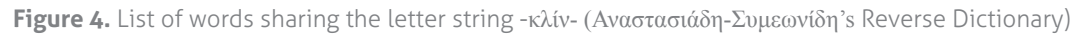

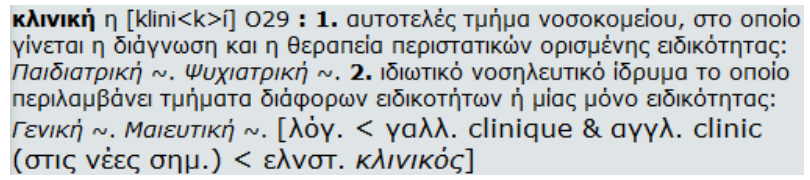

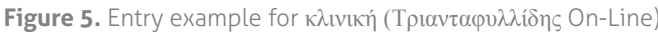

The teacher or learner can draw and distribute the final word list according to different criteria or dimensions: e.g. typicality or salience, derivative formation (prefixes, suffixes), word types, semantic criteria, etc.

In Figure 7, the semantic and formal resemblance of the words clinic, clínica and $\kappa \lambda \imath v i \kappa \eta$ was considered a relevant symbolic unit in order to become a headword. Each infographical object derived from the central nodes ( $\kappa \lambda \imath v i k \eta$, $\kappa \lambda i v \eta)$ is a representation of concepts in a family resemblance context. A clinic is a place where beds can be found and, not surprisingly, the Greek etymon of $\kappa \lambda l v ı \kappa \eta$ (clinic) is again etymologically related to the concept bed, which, in turn, is best expressed as kiiv (the second central infographical object), which is the learned word for bed. 


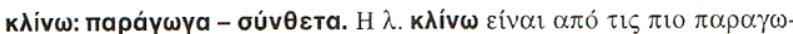

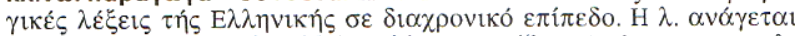

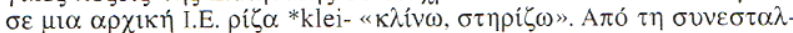

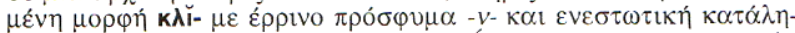

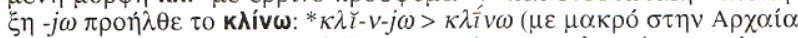

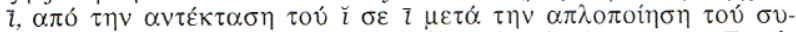

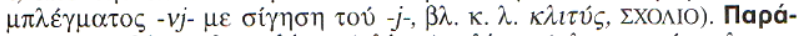

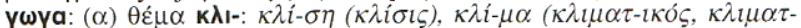
$\iota \sigma \mu \delta \varsigma, \kappa \lambda \imath \mu \alpha \tau$ - $\sigma \tau \imath \kappa o ́ \varsigma, ~ \kappa \lambda \imath \mu \alpha \tau-i \zeta o \mu \alpha \imath), \kappa \lambda i ́ \mu \alpha \kappa \alpha(<\alpha \rho \chi . \kappa \lambda i ́ \mu \alpha \xi$,

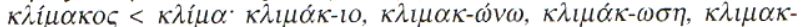

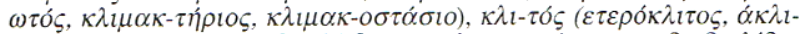

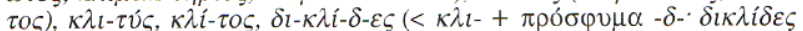

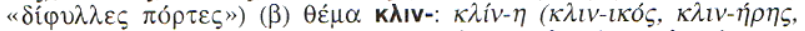
$\kappa \lambda l v-o \sigma \kappa \varepsilon \pi \dot{\alpha} \sigma \mu \alpha \tau \alpha), \delta i-\kappa \lambda l v o \varsigma, \mu o v o ́-\kappa \lambda l v o \varsigma, \kappa \lambda l v-\alpha ́ \alpha l,-\kappa \lambda l v-\eta \dot{\varsigma}(\varepsilon \pi t-$

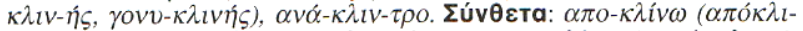

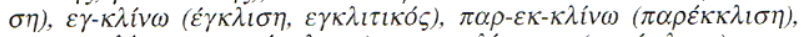
$\pi \alpha \rho-\varepsilon \gamma-\kappa \lambda i v \omega(\alpha-\pi \alpha \rho \varepsilon \gamma \kappa \lambda l \tau O \varsigma), \kappa \alpha \tau \alpha-\kappa \lambda i v o \mu \alpha l$ ( $\kappa \alpha \tau \alpha \dot{\alpha} \kappa \lambda \iota \sigma \eta), v \pi O-$ $\kappa \lambda i ́ v o \mu \alpha \imath$ ( $(\pi \delta \delta \kappa \lambda l \sigma \eta), \alpha v \alpha-\kappa \lambda i ́ v o \mu \alpha l(\alpha v \alpha ́ \kappa \lambda l \sigma \eta)$.

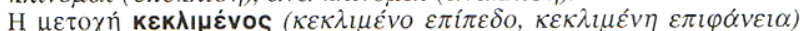

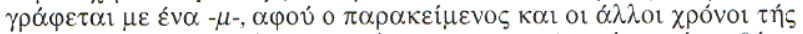

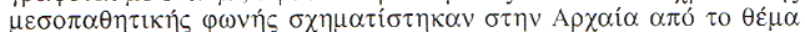

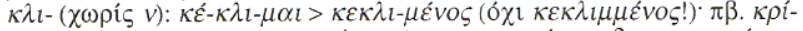

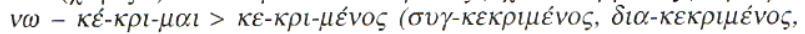
$\varepsilon \gamma-\kappa \varepsilon \kappa \rho \iota \mu \varepsilon ́ v o \varsigma)$.

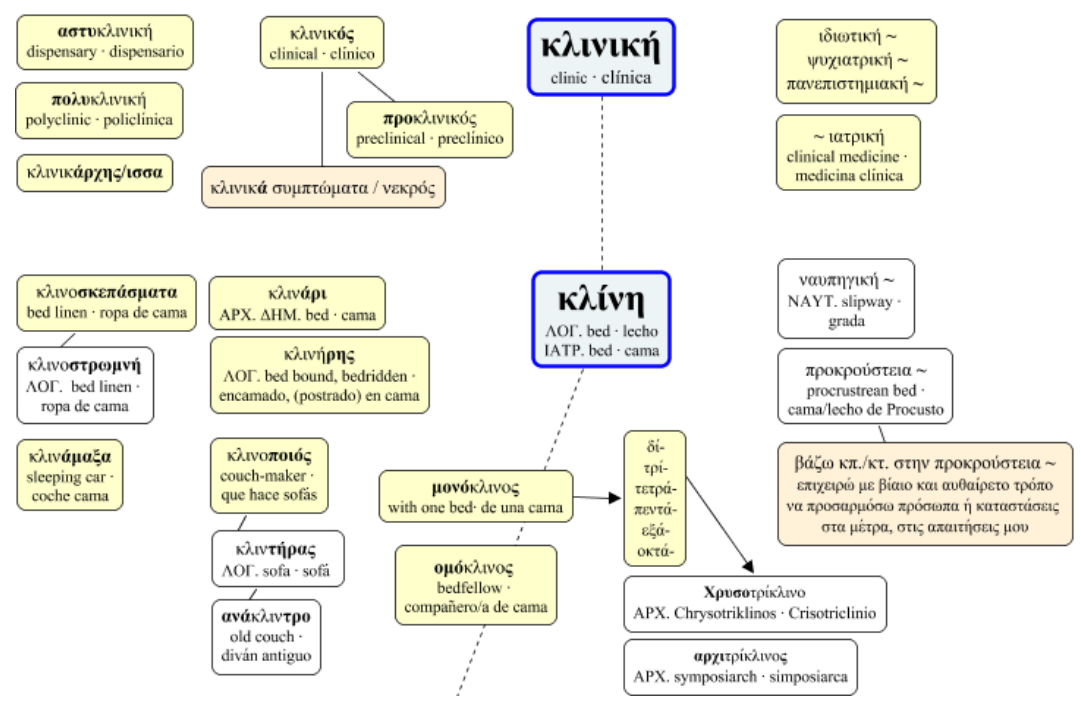

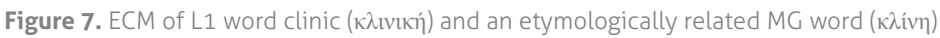


In the case of $\kappa \lambda \imath v \imath \kappa \eta$, on the left-hand side, the main criteria for derivatives

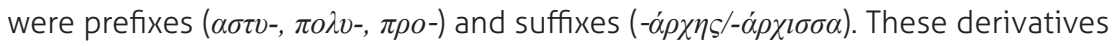
are grouped semantically in terms of space and colour, thus becoming subnodes with related words or expressions of their own (marked with arrows). The majority of these conceptual objects also contains English and Spanish equivalents to facilitate the comprehension of the readers, not to be learnt as the only possible equivalents.

The MG learner or teacher can add frequent collocations or phrases, such as private clinic, psychiatric clinic, university clinic, and other uses of the same

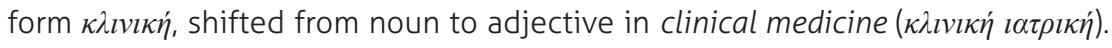
Of course, this distribution of the nodes is dynamic. Categories, collocations, positions and colours can be goal-derived or even ad hoc, i.e. not well-established in memory but are instead newly created to achieve a novel goal (Barsalou 1985, 1983 apud Barsalou 1987).

The goal of the ECM in Figure 7 is to show the relation potential of a learned

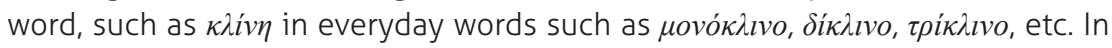
the context of "booking a hotel room in Greece" these words are commonplace. It goes without saying that each ECM could be extended with proverbs or more specific sub-headwords, or be reused for different tasks. For example, Figure 7 can serve as an introduction to medical terminology in MG. Markers such as $\Lambda О \Gamma$. (learned term/expression) and IATP. (medical term/expression) were added. The common word for bed in MG, however, is $\kappa \rho \varepsilon(\beta) \beta \alpha \dot{\alpha} \tau$, which could be the headword of another unrelated ECM.

In addition to this, colours are a useful tool to express or highlight semantic or derivative relations, new attributes, or values to the headword (cf. Hampton and Dubois 1993: 15). For example, in Figures 7 and 8 colours were used to point out which items were more relevant for the task of the lesson.

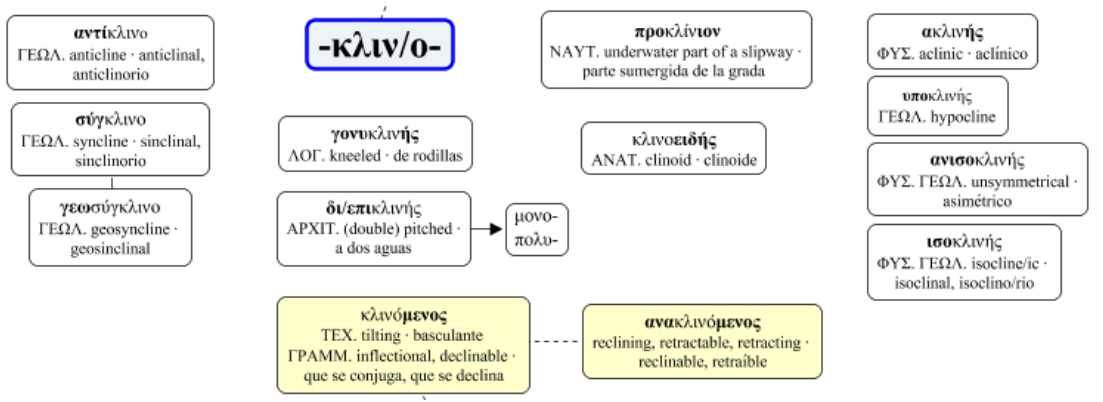

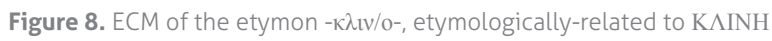


In Figure 8, the etymological relation of etymon - $\kappa \lambda \imath v / o$ - with KAINH and KAINIKH is expressed with a dotted line. This indicates that, even though the same etymon can be found in most objects of Figure 7, the semantic content varies from BED to INCLINATION. We believe this semantic distribution is more useful

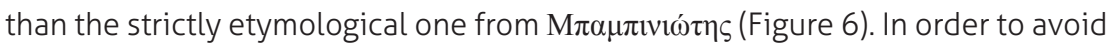
confusion, we recommend these items be grouped separately. In contrast with popular words ( $\triangle \mathrm{HM}$.) in Figure 7 , almost all derivatives of this etymon are rather learned $(\Lambda \mathrm{O}$.) or belong to a specific domain, such as anatomy, archaeology, architecture, geology, navigation, technology, and physics. These domains are marked in Greek capitals (ANAT., APX., APXIT., $\Delta$ HМ., ГЕ $\Omega \Lambda$., ГРАММ., $\Lambda$ ОГ, NAYT., TEX., $\Phi Y \Sigma$.).

\section{Conclusions and Future Research}

It goes without saying that a great part of MG etymons and lexicon has spread to almost all Occidental languages. As a result, the learner's L1 lexicon coming from Greek etymons can be easily identified and thus exploited. The ECA takes advantage of the learner's previous knowledge in order to provide meaning, prototypicality, and family resemblance to 'empty' words', 'irrational' orthography and 'isolated' expressions. Since a great amount of MG words are related to each other both semantically and orthographically, they can be grouped and structured so that they can be retrieved more easily, as proposed in our ECMs.

While elaborating an ECM, learners get involved in a challenging purpose that makes vocabulary items clearer according to their own needs and intelligences. Learners are drawn into participation in order to find rules, central nodes and family resemblances on their own: How are these words/concepts related? How can I relate them in order to retrieve them best according to my needs and background? Can I find a rule or do I have to learn these items independently? The outcome of this reasoning is a pictorial or diagrammatical device which, in turn, can be re-used for learning and refreshing already controlled information. Future research will explore feasible applications of ECMs in lexicography.

3 l.e. words that initially appear to be semantically void or obscure to a layperson, but in fact are not if their morphology and etymology are examined. 


\section{References}

Aitchison, J. 2003. Words in the mind. An introduction to the mental lexicon. 3rd edition (1st edition 1987). Oxford and New York: Blackwell.

Armstrong, T. 2006. Inteligencias múltiples en el aula. Guía práctica para educadores. Barcelona: Paidós.

Barsalou, L.W. 1987. The instability of graded structure: Implications for the nature of concepts. In U. Neisser (ed.), Concepts and conceptual development: Ecological and intellectual factors in categorization. Cambridge: Cambridge University Press, 101-140.

Barsalou, L.W. 2005. Situated conceptualization. In H. Cohen and C. Lefebvre (eds.), Handbook of categorization in cognitive science. St. Louis: Elsevier, 619-650.

Bowker, L. 1997. Multidimensional classification of concepts and terms. In S.E. Wright and G. Budin (eds.), Handbook of Terminology Management: Basic Aspects of Terminology Management. Amsterdam/Philadelphia: John Benjamins, 133143.

Faber, P. and C. Jiménez Hurtado. 2004. Traducción, lenguaje y cognición. Granada: Comares.

Gardner, H. 2008. Las cinco mentes del futuro. Barcelona: Paidós.

Goswami, U., C. Porpodas and S. Wheelwright. 1997. Children's orthographic representations in English and Greek. European Journal of Psychology of Education 12(3): 273-292.

Hampton, J. and D. Dubois. 1993. Psychological Models of Concepts: Introduction. In I. Van Mechelen, J. Hampton, R.S. Michalski and P. Theuns (eds.), Categories and 
Concepts. Theoretical Views and Inductive Data Analysis. San Diego: Academic Press.

Hatch, E. and C. Brown. 1995. Vocabulary, semantics, and language education. Cambridge: Cambridge University Press.

Heit, E. 1997. Knowledge and Concept Learning. In K. Lamberts and D. Shanks (eds.), Knowledge, concepts, and categories. Hove, UK: Psychology Press.

Hurtado Albir, A. 2007. Traducción y traductología. Introducción a la traductología. Madrid: Cátedra.

Ibáñez, M.E., J.L. Casado and A. Masiá (1997). Estudio metodológico del griego moderno como lengua extranjera. In M. Morfakidis and I. García Gálvez (eds.), Estudios Neogriegos en España e Iberoamérica. Granada: Athos-Pérgamos, Fundación de la Cultura Helénica, Sociedad Hispánica de Estudios Neogriegos, 107-113.

Johnson, M. 1987. The body in the mind: The bodily basis of meaning, imagination, and reason. Chicago: University of Chicago Press.

Kageura, K. 1997. Multifaceted/Multidimensional concept systems. In S.E. Wright and G. Budin (eds.), Handbook of Terminology Management: Basic Aspects of Terminology Management. Amsterdam/Philadelphia: John Benjamins, 119-132.

Kleiber, G. 1990. La sémantique du prototype. Paris: P.U.F.

Lakoff, G. 1982. Categories and Cognitive Models. Cognitive Science Program, Institute of Cognitive Studies, Berkeley: University of California.

Lakoff, G. 1987. Women, Fire and Dangerous Things. What Categories reveal about the Mind. Chicago \& London: University of Chicago Press.

Langacker, R.W. 1987. Foundations of Cognitive Grammar Vol. 1: Theoretical Prerequisites. Stanford: Stanford University Press.

Mervis, C.B. and J.R. Pani. 1980. Acquisition of Basic Object Categories. Cognitive Psychology 12: 496-522.

Murphy, M.L. 2003. Semantic Relations and the Lexicon. Cambridge University Press: Cambridge. 
Picht, H. and J. Draskau. 1985. Terminology: An Introduction. Guildford: University of Surrey.

Polychrou, T. 1997. Aprendizaje y aplicación. Selección metodológica en la didáctica del griego moderno. In M. Morfakidis and I. García Gálvez (eds.), Estudios Neogriegos en España e Iberoamérica. Granada: Athos-Pérgamos, Fundación de la Cultura Helénica, Sociedad Hispánica de Estudios Neogriegos, 125-128.

Randall, M. 2007. Memory, Psychology and Second Language Learning. John Benjamins: Amsterdam / Philadelphia.

Robinson, D. 2003. Becoming a Translator: An Introduction to the Theory and Practice of Translation. London: Routledge.

Rodríguez Adrados, F. 1999. Historia de la lengua griega: de los orígenes a nuestros días. Madrid: Gredos.

Rogers, M. 2004. Multidimensionality in concepts systems: a bilingual textual perspective. Terminology 10(2): 215-240.

Rosch, E. 1973. On the Internal Structure of Perceptual and Semantic Categories. In T.E. Moore (ed.), Cognitive Development and the Acquisition of Language. New York: Academic Press, 111-144.

Rosch, E. and C.B. Mervis. 1975. Family Resemblances. Studies in the Internal Structure of Categories. Cognitive Psychology 1: 573-605.

Rosch, E., C. Simpson and R.S. Miller. 1976. Structural Bases of Typicality Effects. Journal of Experimental Psychology: Human Perception and Performance 2(4): 491-502.

Seidenberg, M.S. and J.L. McClelland. 1989. A Distributed, Developmental Model of Word Recognition and Naming. Psychological Review 96: 523-568.

Sperber, D. and D. Wilson. 1986. Relevance: Communication and Cognition. Oxford: Blackwell.

Sygmund, D. 2006. The Theory of Multiple Intelligences and its Influence on our Learning and Teaching. In A.J. Moya Guijarro, J.I. Albentosa Hernández, C. Harris (coords.), La enseñanza de las lenguas extranjeras en el Marco Europeo. Cuenca: Universidad de Castilla-La Mancha. 
Ungerer, F. and H.-J. Schmid. 1996. An introduction to cognitive linguistics. London: Longman.

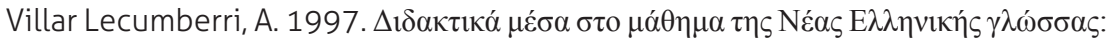

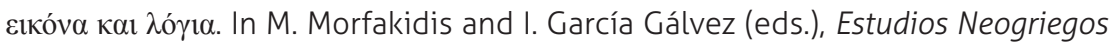
en España e Iberoamérica. Granada: Athos-Pérgamos, Fundación de la Cultura Helénica, Sociedad Hispánica de Estudios Neogriegos, 115-123.

Widdowson, H.G. 2002. Aspects of Language Teaching. Oxford: Oxford University Press.

\section{Dictionaries}

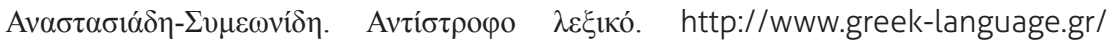
greekLang/modern_greek/tools/lexica/reverse/

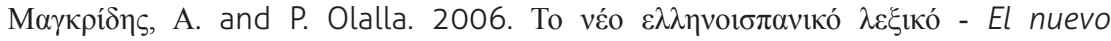
diccionario griego-español.

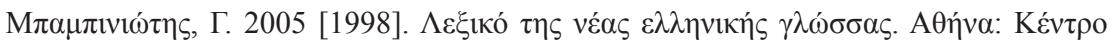

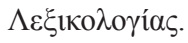

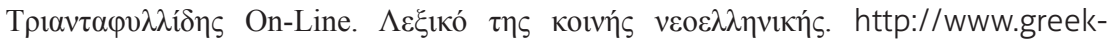
language.gr/greekLang/modern_greek/tools/lexica/triantafyllides/ 